\title{
Impacts of Symmetrical and Asymmetrical Voltage Sags on DFIG-Based Wind Turbines Considering Phase-Angle Jump, Voltage Recovery, and Sag Parameters
}

\author{
Mansour Mohseni, Student Member, IEEE, Syed M. Islam, Senior Member, IEEE, \\ and Mohammad A. S. Masoum, Senior Member, IEEE
}

\begin{abstract}
This paper presents a new analysis into the impacts of various symmetrical and asymmetrical voltage sags on doubly fed induction generator (DFIG)-based wind turbines. Fault ridethrough requirements are usually defined by the grid codes at the point of common coupling (PCC) of wind farms to the power network. However, depending on the network characteristics and constraints, the voltage sag conditions experienced at the wind generator terminals can be significantly different from the conditions at the PCC. Therefore, it is very important to identify the voltage sags that can practically affect the operation of wind generators. Extensive simulation studies are carried out in MATLAB/Simulink to investigate the transient overshoots and ripples that appear in the rotor current and dc-link voltage when the DFIG is subjected to various types of (a)symmetrical faults. For the first time, the impacts of phase-angle jump and operational constraints of circuit breakers are examined. Furthermore, the influences of sag parameters including type, initial point-on-wave instant, depth, and impedance angle are investigated. Complementary theoretical analyses are also presented to support the validity of observations made in the simulation studies.
\end{abstract}

Index Terms-Doubly fed induction generator (DFIG), fault ride-through (FRT) capability, phase-angle jump, sag parameters, voltage sag recovery.

\section{NOMENCLATURE}

Vectors and Symbols

$\alpha, \psi \quad$ Impedance angle, fault current angle.

$t_{i}, t_{f} \quad$ Initial and final point-on-wave instants.

$\mathbf{V}, \mathbf{I}, \boldsymbol{\Phi}$ Voltage, current, and flux space vectors.

Subscripts

$s, r \quad$ Stator and rotor windings.

,+- Positive- and negative-sequence components.

Superscripts

$g, r$ Arbitrary and rotor reference frames.

Manuscript received April 30, 2010; revised August 11, 2010; accepted October 4, 2010. Date of current version June 29, 2011. Recommended for publication by Associate Editor Z. Chen.

The authors are with the Department of Electrical and Computer Engineering, Curtin University of Technology, Perth 6101, Australia (e-mail: mansour. mohseni@postgrad.curtin.edu.au; s.islam@curtin.edu.au; m.masoum@curtin. edu.au).

Color versions of one or more of the figures in this paper are available online at http://ieeexplore.ieee.org.

Digital Object Identifier 10.1109/TPEL.2010.2087771

\section{INTRODUCTION}

$\mathbf{T}$ HE past decade has seen the emergence of wind as the most dynamically growing energy source and doubly fed induction generators (DFIGs) as the most popular technology used in wind energy conversion systems. The DFIG concept has several advantages as compared to the fixed-speed generators, including maximized power capture, reduced mechanical stresses on the turbine, and reduced acoustical noise. In addition, this technology is more economically viable than the full-converter variable-speed concept since it employs voltagesource converters (VSCs) rated at 30\%-35\% of the generator size for the rotor speed variation range of $\pm 25 \%$ [1], [2]. Note that in the full-converter wind generators, the gearbox can be eliminated to reduce the cost and complexity of the system. The DFIG concept suffers from a sheer vulnerability to the grid faults and special countermeasures must be taken to safeguard it against various voltage sag conditions.

In the past, the wind power penetration level was extremely small compared to the conventional generation systems, and grid codes did not include any connection requirements for wind energy conversion systems. Therefore, wind generators were allowed to disconnect from the grid during the fault, using an active resistance called "crowbar" [2]. However, this approach can cause serious stability problem in power networks with a high integration level of wind generation systems. To avoid this problem, system operators in many countries have recently established more stringent connection requirements for wind generators integrated into the transmission or distribution networks. Specifically, modern grid codes define the voltagetime profiles, for which wind farms must remain connected to the grid, commonly referred to as the fault ride-through (FRT) requirements [3]. Fig. 1 shows a practical example of the FRT specifications required by Spanish system operators, REE, for wind generators connected to the transmission system $(V \geq$ $66 \mathrm{kV}$ ) [4]: a wind farm shall remain connected to the transmission system under the sag conditions when the voltage measured at the high-voltage (HV) terminals of the grid-connected transformer remains above the dashed line for two-phase-to-ground faults and above the solid line for other types of faults. It is clear that Point C, with $20 \%$ remnant voltage, is the most severe sag condition requested by the Spanish Grid Code.

Achieving recent FRT requirements is a significant technical issue for wind generator manufacturers. To fulfill this objective, 


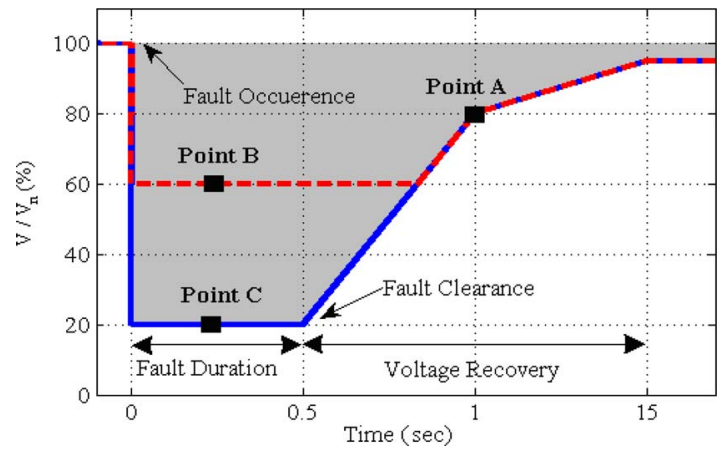

Fig. 1. FRT requirements of wind farms at the PCC - Spanish Grid Code.

a thorough insight into the FRT specifications and what they practically request at the wind generators terminals is of the utmost importance. The relevant features and operational constraints of power networks must be taken into account including the effects of transformers' configuration, submarine ac cables used in offshore wind farms, and fault-clearing mechanism of circuit breakers. This would help to accurately identify the realistic voltage sag conditions that are expected at wind generator terminals under different types of faults. Following this, detailed transient models of wind generators can be incorporated to predict the evolution of electrical and mechanical variables under different sag conditions. In this way, the difficulties of successful FRT will be identified, and modifications to the conventional control techniques can be suggested to address these problems and enhance the FRT capability of wind generators.

The operation of DFIG-based wind turbines under various fault conditions has been comprehensively investigated in the last decade [5]-[20]. Initial works were mainly aimed to develop reduced-order models for DFIG-based wind turbines in network stability studies [5]-[9]. This type of model is restricted to the fundamental frequency response of the DFIG under three-phase faults. The FRT capability of DFIG-based wind turbines subjected to three-phase faults has been studied in [10] and [11]. However, it was shown that asymmetrical faults, e.g., phase-tophase faults, are more likely to occur and could have more detrimental impacts on the DFIG [12]-[14]. Therefore, recent works have focused on the detailed transient response and FRT capability of DFIGs under asymmetrical sag conditions [13]-[20]. The main shortcoming is that most of the reported studies examine very limited sag conditions, which cannot adequately represent the broad range of FRT requirements specified in grid codes. The gap becomes even more evident in [15], where simulation studies are carried out for the voltage sag conditions that cannot be practically experienced at the DFIG terminals. Moreover, it is known that not only the magnitude of the voltage, but also its phase angle can be affected by faults in the grid; particularly for wind farms directly connected to the distribution systems or offshore wind farms with ac submarine cables [21]. Detrimental impacts of this phenomenon, referred to as "phaseangle jump," on the operation of DFIG-based wind farms have not been explored in the literature. These problems have been briefly discussed in [21], but no theoretical or simulation studies were presented to support the work. Finally, the effects of

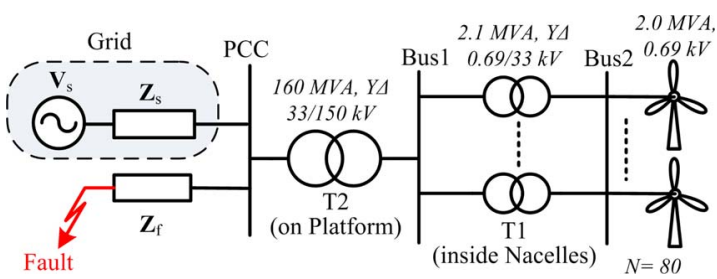

Fig. 2. Voltage divider model (italic figures are the real parameters for HornsRev Wind Farm and " $N$ " is the total number of wind turbines).

voltage-recovery process and sag parameters on DFIG-based wind turbine have not been investigated in the literature.

This paper aims to address the aforementioned shortcomings and thoroughly examine the impacts of various (a)symmetrical voltage sags on the operation of DFIG-based wind turbines. Section II presents the characterization and classification of various voltage sag conditions, considering the transformers' configurations, impedance angle of the grid, and the natural current zero-crossing operation of circuit breakers. Section III presents a brief theoretical study of the DFIG system under grid faults, which will be used to analyze the simulation results. In Section IV, the wind generator is simulated in MATLAB/ Simulink and is subjected to various sag conditions to investigate the transient overshoots and steady-state ripples that appear in the rotor current and dc-link voltage under different types of faults. This section also examines the effects of phase-angle jump and voltage-recovery process. Finally, Section V investigates the influence of sag parameters (type, initial point-on-wave instant, depth, and impedance angle) on the peak values of the rotor current and dc-link voltage.

\section{Characteristic and Classification of Voltage Sags}

When a fault occurs at some points in the power network, the grid voltage will drop to the lower levels until a protection device trips and circuit breakers isolate the fault. During this interval, wind generators connected to the same bus as the faulted feeder will experience a voltage sag condition. This section aims to characterize and classify the voltage sag conditions caused by different types of faults in the grid.

\section{A. Symmetrical Faults and Phase-Angle Jump}

The voltage-divider model can be used to formulate the voltage sag conditions caused by three-phase faults in radial systems, as shown in Fig. 2 [22]. In this figure, T1 represents the step-up transformer that is located in the nacelle of each wind turbine to increase the low-level voltages generated at the DFIG terminals to the medium voltage used in the collection grid of the wind farm. In cascade to the nacelle transformers, a large step-up transformer (T2), sized at the nominal capacity of the wind farm, will be used to increase the collection-grid voltage to the transmission-level voltage. Real parameters for the transforms used in one of the largest offshore wind farms in the world, Horns Rev, have been shown in Fig. 2 to provide further insight [23]. According to Fig. 2, the voltage at the point of common coupling (PCC), i.e., at the HV side of T2, can be 
defined as follows:

$$
\mathbf{V}_{\mathrm{sag}}=\mathbf{V}_{s} \frac{\mathbf{Z}_{f}}{\mathbf{Z}_{f}+\mathbf{Z}_{s}}
$$

where $\mathbf{V}_{s}$ is the prefault voltage, $\mathbf{Z}_{s}$ is the source impedance at PCC, and $\mathbf{Z}_{f}$ is the impedance between the PCC and fault location. Three-phase sags are normally characterized by the magnitude of the remnant voltage and the duration. However, if the $X / R$ ratios of the impedance $\mathbf{Z}_{s}$ and $\mathbf{Z}_{f}$ are different, the three-phase fault causes not only a drop in the voltage magnitudes, but also a sudden change in the phase angle of the threephase voltage. This phenomenon is referred to as "phase-angle jump" and is defined by

$$
\delta=\arg \left(\mathbf{V}_{\text {sag }}\right)=\arg \left(\mathbf{Z}_{f}\right)-\arg \left(\mathbf{Z}_{s}+\mathbf{Z}_{f}\right) .
$$

For the conventional transmission systems, both $\mathbf{Z}_{s}=R_{s}+$ $j X_{s}$ and $\mathbf{Z}_{f}=R_{f}+j X_{f}$ are mainly formed by overhead transmission lines and large transformers, therefore, the phase-angle jump would be very small. However, for wind farm connected to the distribution systems or offshore wind farms with highvoltage submarine cables, the $X / R$ ratio of the source impedance is noticeably larger than the $\mathbf{Z}_{f}$ impedance. Thus, three-phase faults cause large sudden variations of the voltage phase angles.

If (2) is rewritten with $\mathbf{Z}_{f} / \mathbf{Z}_{s}=\lambda e^{j \alpha}$, it can be observed that the " $\lambda$ " value varies depending on the fault distance, whereas, the " $\alpha$ " parameter is fixed for any given source--fault impedance combination (known as impedance angle). Consequently, a unique relationship between the sag magnitude and its phase-angle jump can be established for any specific impedance angle. It is not practical to consider individual characteristics of each network for testing the FRT capability of wind generators. Therefore, this paper focuses on the typical impedance angles proposed by [22], including $0^{\circ}$ (the most common value for transmission systems), $-20^{\circ}$ (typical value for distribution systems), and $-60^{\circ}$ (the minimum value for wind farms located offshore with submarine/underground AC cables). Fig. 3 shows the relation between the sag magnitude and the corresponding phase-angle jump for various impedance angles. It can be seen that the voltage sag conditions specified in the Spanish Grid Code (e.g., Point B in Fig. 1) are mapped to different voltage vectors depending on the network impedance angle, e.g., to Points $\mathrm{B}_{1}\left(\mathbf{V}_{\mathrm{sag}}=0.6\left\llcorner 0^{\circ}\right), \mathrm{B}_{2}\left(\mathbf{V}_{\mathrm{sag}}=0.6\left\llcorner-12^{\circ}\right)\right.\right.$, and $\mathrm{B}_{3}$ $\left(\mathbf{V}_{\text {sag }}=0.6 \angle-31^{\circ}\right)$ for $\alpha=0^{\circ}, \alpha=-20^{\circ}$, and $\alpha=-60^{\circ}$, respectively. Similar comments can be made about Points A and $\mathrm{C}$.

\section{B. Asymmetrical Faults and Voltage Sag Classification}

If an asymmetrical fault occurs in the power network, six types of voltage sags (types B to G) can appear at the PCC and the wind generator terminals [22]. The phasor expressions of various sag types are given in the Appendix. The magnitude and angle of the characteristic voltage $\left(\mathbf{V}_{\text {sag }}\right)$ define the remnant voltage and phase-angle jump, respectively. In [22], it has been demonstrated that the transformers' configuration cannot affect the voltage sag conditions caused by three-phase grid faults, i.e., sag-type A propagates unchanged throughout the network

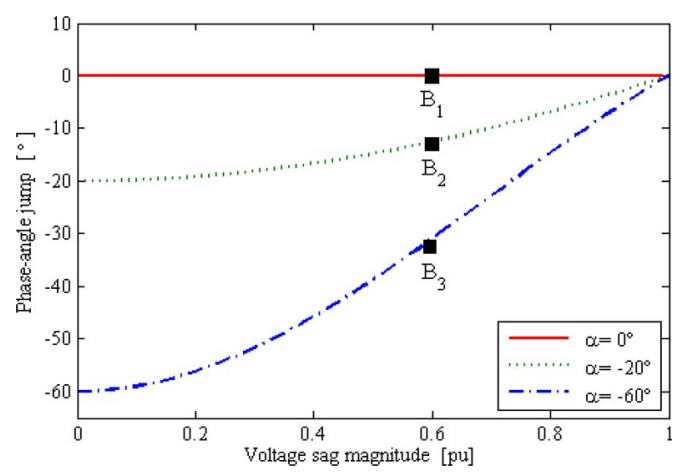

Fig. 3. Voltage sag magnitude versus phase-angle jump for various impedance angles.

TABLE I

Voltage Sag Propagation Inside the Wind Farm

\begin{tabular}{|c||c||c||c|c|}
\hline Fault & Sag at PCC & $\begin{array}{c}\text { Sag at Bus1, } \\
\text { Y } \Delta \text { Trans. }\end{array}$ & $\begin{array}{c}\text { Sag at Bus2, } \\
\text { Y } \Delta \text { Trans. }\end{array}$ & $\begin{array}{c}\text { Sag at Bus2, } \\
\text { Other Trans. }\end{array}$ \\
\hline \hline $3 \Phi$ & Type A & Type A & Type A & Type A \\
\cline { 2 - 5 }$\Phi-g$ & Type B & Type C* & Type D* & Type C* \\
\cline { 2 - 5 }$\Phi-\Phi$ & Type C & Type D & Type C & Type D \\
\cline { 2 - 5 } & Type E & Type F & Type G & Type F \\
\hline
\end{tabular}

* The characteristic voltage is not equal to $\mathbf{V}_{\mathrm{sag}}$ but to $\left(1 / 3+2 / 3 \mathbf{V}_{\mathrm{sag}}\right)$.

from the PCC toward Bus 1 and Bus 2 in Fig. 2. However, the voltage sag experienced at the wind generator terminals during asymmetrical faults can be substantially different from the PCC, due to the transformers' configuration. The coupling transformer (T2) is usually connected in $Y \Delta$ configuration, which filters out the zero-sequence component in the secondary side (see Bus 1 in Fig. 2). Afterward, the sag type at Bus 2, experienced at the wind generator terminals, is defined based on the configuration of the nacelle transformer, as listed in the last two columns of Table I. It is clear that sag types B and E cannot reach the generator terminals as they include zero-sequence components. On the other hand, sag types D, F, and $\mathrm{G}$ will be observed only if the transformers' configurations are taken into account. Finally, it is concluded that to thoroughly examine the operation of DFIG-based wind turbines under fault conditions, the wind generator must be subjected to the sag types of $A, C^{*}, D^{*}, C, D$, $\mathrm{F}$, and $\mathrm{G}$.

\section{Fault Clearance and Voltage-Recovery Process}

It is known that the protection relays might trip at any time during the fault, while the pole of the circuit breakers can only function and isolate the fault at the natural zero-crossing points of the corresponding phase current. As a result, grid faults that involve more than two phases (e.g., two-phase to ground, threephase, and three-phase-to-ground faults) will be cleared in two or three steps. This is because when the circuit breaker operates in one phase, the fault will develop into another type and the full voltage recovery will take place with the operation of circuit breakers in other faulted phases. For example, if a two-phase-toground fault occurs between phases $a$ and $b$, the circuit breaker can first operate in the zero crossing point of phase $a$; then the 
TABLE II

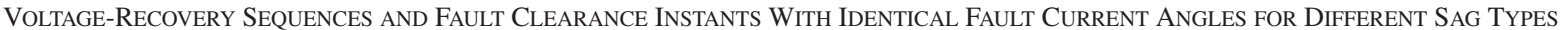

\begin{tabular}{|c|c|c|c|c|c|}
\hline Sag Type & Sequence of sags* & $\begin{array}{c}\text { First recovery } \\
\omega t_{f l}\end{array}$ & $\begin{array}{c}\text { Second recovery } \\
\omega t_{f 2}\end{array}$ & $\begin{array}{c}\text { Third recovery } \\
\omega t_{j 3} \\
\end{array}$ & Fault-clearing delay \\
\hline$A_{1}$ & $\mathrm{~A}_{1} \rightarrow \mathrm{C}_{\mathrm{a}}$ & n. $360^{\circ}-\alpha_{a}+\psi$ & n. $360^{\circ}-\alpha_{a}+\psi+90^{\circ}$ & - & $\omega t_{f 2}-\omega t_{f 1}=90^{\circ}$ \\
\hline $\mathrm{A}_{2}$ & $\mathrm{~A}_{2} \rightarrow \mathrm{D}_{\mathrm{a}}$ & n. $360^{\circ}-\alpha_{a}+\psi+90^{\circ}$ & n. $360^{\circ}-\alpha_{a}+\psi+180^{\circ}$ & - & $\omega t_{f 2}-\omega t_{f 1}=90^{\circ}$ \\
\hline $\mathrm{A}_{3}$ & $\mathrm{~A}_{3} \rightarrow \mathrm{E}_{2 \mathrm{a}} \rightarrow \mathrm{B}_{\mathrm{b}}$ & n. $360^{\circ}-\alpha_{a}+\psi$ & n. $360^{\circ}-\alpha_{\mathrm{a}}+\psi+60^{\circ}$ & n. $360^{\circ}-\alpha_{\mathrm{a}}+\psi+120^{\circ}$ & $\omega t_{j 3}-\omega t_{f 1}=120^{\circ}$ \\
\hline $\mathrm{A}_{4}$ & $\mathrm{~A}_{4} \rightarrow \mathrm{F}_{2 \mathrm{a}} \rightarrow \mathrm{C}_{\mathrm{b}}{ }^{*}$ & n. $360^{\circ}-\alpha_{a}+\psi+90^{\circ}$ & n. $360^{\circ}-\alpha_{a}+\psi+150^{\circ}$ & n. $360^{\circ}-\alpha_{a}+\psi+210^{\circ}$ & $\omega t_{f 3}-\omega t_{f 1}=120^{\circ}$ \\
\hline $\mathrm{A}_{5}$ & $\mathrm{~A}_{5} \rightarrow \mathrm{G}_{2 \mathrm{a}} \rightarrow \mathrm{D}_{\mathrm{b}}^{*}$ & n. $360^{\circ}-\alpha_{a}+\psi$ & n. $360^{\circ}-\alpha_{\mathrm{a}}+\psi+60^{\circ}$ & n. $360^{\circ}-\alpha_{\mathrm{a}}+\psi+120^{\circ}$ & $\omega t_{f 3}-\omega t_{f 1}=120^{\circ}$ \\
\hline $\mathrm{B}_{\mathrm{a}}$ & - & n. $360^{\circ}-\alpha_{a}+\psi$ & - & - & - \\
\hline $\mathrm{C}_{\mathrm{a}}$ or $\mathrm{C}_{\mathrm{a}}^{*}$ & - & n. $360^{\circ}-\alpha_{a}+\psi+90$ & - & - & - \\
\hline $\mathrm{D}_{\mathrm{a}}$ or $\mathrm{D}_{\mathrm{a}}{ }^{*}$ & - & n. $360^{\circ}-\alpha_{a}+\psi$ & - & - & - \\
\hline $\mathrm{E}_{\mathrm{la}}$ & $\mathrm{E}_{1 \mathrm{a}} \rightarrow \mathrm{B}_{\mathrm{c}}$ & n. $360^{\circ}-\alpha_{a}+\psi+120^{\circ}$ & n. $360^{\circ}-\alpha_{\mathrm{a}}+\psi+240^{\circ}$ & - & $\omega t_{f 2}-\omega t_{f 1}=120^{\circ}$ \\
\hline $\mathrm{E}_{2 \mathrm{a}}$ & $\mathrm{E}_{2 \mathrm{a}} \rightarrow \mathrm{B}_{\mathrm{b}}$ & n. $360^{\circ}-\alpha_{\mathrm{a}}+\psi-120^{\circ}$ & n. $360^{\circ}-\alpha_{\mathrm{a}}+\psi-60^{\circ}$ & - & $\omega t_{f 2}-\omega t_{f 1}=60^{\circ}$ \\
\hline $\mathrm{F}_{1 \mathrm{a}}$ & $\mathrm{F}_{1 \mathrm{a}} \rightarrow \mathrm{C}_{\mathrm{c}}^{*}$ & n. $360^{\circ}-\alpha_{a}+\psi-150^{\circ}$ & n. $360^{\circ}-\alpha_{a}+\psi-30^{\circ}$ & - & $\omega t_{f 2}-\omega t_{f 1}=120^{\circ}$ \\
\hline $\mathrm{F}_{2 \mathrm{a}}$ & $\mathrm{F}_{2 \mathrm{a}} \rightarrow \mathrm{C}_{\mathrm{b}}^{*}$ & n. $360^{\circ}-\alpha_{\mathrm{a}}+\psi+150^{\circ}$ & n. $360^{\circ}-\alpha_{a}+\psi+210^{\circ}$ & - & $\omega t_{f 2}-\omega t_{f 1}=60^{\circ}$ \\
\hline $\mathrm{G}_{1 \mathrm{a}}$ & $\mathrm{G}_{1 \mathrm{a}} \rightarrow \mathrm{D}_{\mathrm{c}}^{*}$ & n. $360^{\circ}-\alpha_{a}+\psi+120^{\circ}$ & n. $360^{\circ}-\alpha_{a}+\psi+240^{\circ}$ & - & $\omega t_{f 2}-\omega t_{f 1}=120^{\circ}$ \\
\hline $\mathrm{G}_{2 \mathrm{a}}$ & $\mathrm{G}_{2 \mathrm{a}} \rightarrow \mathrm{D}_{\mathrm{b}}{ }^{*}$ & n. $360^{\circ}-\alpha_{\mathrm{a}}+\psi-120^{\circ}$ & n. $360^{\circ}-\alpha_{a}+\psi-60^{\circ}$ & - & $\omega t_{f 2}-\omega t_{f 1}=60^{\circ}$ \\
\hline
\end{tabular}

* Sag types $\mathrm{B}_{\mathrm{a}}, \mathrm{C}_{\mathrm{a}}, \mathrm{D}_{\mathrm{a}} \ldots$. denote that space vectors $\mathbf{V}_{b n}$ and $\mathbf{V}_{c n}$ are symmetrical with respect to phase $a$, as in Table $\mathrm{V}$.

Sag types $\mathrm{B}_{\mathrm{b}}, \mathrm{C}_{\mathrm{b}}, \mathrm{D}_{\mathrm{b}} \ldots$. denote that space vectors $\mathbf{V}_{a n}$ and $\mathbf{V}_{c n}$ are symmetrical with respect to phase $b$.

Sag types $\mathrm{B}_{\mathrm{c}}, \mathrm{C}_{\mathrm{c}}, \mathrm{D}_{\mathrm{c}} \ldots$. denote that space vectors $\mathbf{V}_{a n}$ and $\mathbf{V}_{b n}$ are symmetrical with respect to phase $c$.

single-phase-to-ground fault in phase $b$ will be cleared, leading to the full voltage recovery.

In [24], fourteen types of sags corresponding to different possibilities of voltage recovery are listed, given in Table II. It can be seen that the three-phase faults that generate type A voltage sags can be cleared in five different ways (involving two or three steps), two-phase-to-ground faults that generate types $\mathrm{E}, \mathrm{F}$, or $\mathrm{G}$ voltage sags can be cleared in two different ways (involving two steps), and faults that generate other sag types will be cleared in a single way. In Table II, " $t$ " is the initial point-on-wave instant that the fault occurs and " $t_{f 1}$ " is the final point-on-wave instant that the first pole of the circuit breaker clears the fault. If the fault is to be cleared in two or three steps, " $t_{f 2}$ " and " $t_{f 3}$ " will be included to represent the instants that the second and third phases of the circuit breaker clear the fault, respectively. Note that the final point-on-wave instant $\left(t_{f 1}\right)$ is defined according to the fault current angle $(\psi)$ and the other two recovery instants $\left(t_{f 2}\right.$ and $\left.t_{f 3}\right)$ are delayed by $60^{\circ}, 90^{\circ}$, or $120^{\circ}$ with respect to $t_{f 1}$. The typical value of the fault current angle is equal to $75^{\circ}-85^{\circ}$ for overhead transmission systems and $45^{\circ}-60^{\circ}$ for distributions systems or transmission systems with submarine/underground cables. It can be seen that the voltagerecovery instant is discrete and nearly constant for any network with a given fault current angle $\psi$ [24].

\section{TheORETICAL ANALYSIS OF THE DFIG UNDER GRID FAULTS}

This section presents the theoretical analysis of the DFIG operation under various types of voltage sags to support the validity of simulation studies. In DFIG-based wind turbines, the stator winding is directly connected to the nacelle transformer, whereas the three-phase wound rotor is supplied, via slip rings, from a four-quadrant pulse width modulation (PWM) converter with controllable voltage magnitude and frequency. Consequently, the stator remains constant at the grid fundamental frequency, while the generator operates at variable speeds.
The stator-flux-oriented vector control has so far proven to be the most popular technique used in DFIG-based wind turbines [25]. This control approach is structured in a hierarchical double-closed-loop strategy. The outer power control loop is employed to achieve an independent control of the electrical torque (active power) and the machine excitation (reactive power) [25], [26]. In cascade to the power control loop, synchronous frame PI current regulators with feed-forward decoupling parts will be used to control the rotor current vector. For this field-oriented control method, the $d$-axis of the synchronous frame is aligned with the stator-flux space vector, rotating anticlockwise at the speed of $\omega_{s}\left(\omega=\omega_{s}\right)$.

Fig. 4(a) shows the " $\Gamma$-form" equivalent circuit of the machine that has been used in this paper for the DFIG modeling [27]. The stator- and rotor-voltage vectors in the arbitrary frame can be defined as follows:

$$
\begin{aligned}
\mathbf{V}_{s}^{g} & =R_{s} \mathbf{I}_{s}^{g}+\frac{d \boldsymbol{\Phi}_{s}^{g}}{d t}+j \omega \cdot \boldsymbol{\Phi}_{s}^{g} \\
\mathbf{V}_{r}^{g} & =R_{r} \mathbf{I}_{r}^{g}+\frac{d \boldsymbol{\Phi}_{r}^{g}}{d t}+j\left(\omega-\omega_{r}\right) \cdot \boldsymbol{\Phi}_{r}^{g}
\end{aligned}
$$

where " $\omega$ " is the angular speed of the arbitrary frame, and subscripts " $s$ " and " $r$ " distinguish quantities or parameters on the stator and rotor sides, respectively. The flux space vectors are defined as follows:

$$
\begin{aligned}
& \mathbf{\Phi}_{s}^{g}=L_{m}\left(\mathbf{I}_{s}^{g}+\mathbf{I}_{r}^{g}\right)=L_{m} \mathbf{I}_{m}^{g} \\
& \mathbf{\Phi}_{r}^{g}=L_{\sigma} \mathbf{I}_{r}^{g}+L_{m}\left(\mathbf{I}_{s}^{g}+\mathbf{I}_{r}^{g}\right)
\end{aligned}
$$

where $L_{m}$ and $L_{\sigma}$ are the magnetizing and leakage inductances. Using (5) and (6), the rotor-voltage vector in the arbitrary frame is obtained as follows:

$$
\mathbf{V}_{r}^{g}=R_{r} \mathbf{I}_{r}^{g}+L_{\sigma} \frac{d \mathbf{I}_{r}^{g}}{d t}+\frac{d \mathbf{\Phi}_{s}^{g}}{d t}+j\left(\omega-\omega_{r}\right) \cdot\left(L_{\sigma} \mathbf{I}_{r}^{g}+\boldsymbol{\Phi}_{s}^{g}\right) .
$$


The $\mathbf{V}_{r}$ vector can be expressed in the rotor frame by substituting $\omega=\omega_{r}$ in $(7)$

$$
\mathbf{V}_{r}^{r}=\mathbf{V}_{\text {ro }}^{r}+\left(R_{r} \mathbf{I}_{r}^{r}+L_{\sigma} \frac{d \mathbf{I}_{r}^{r}}{d t}\right), \quad \text { where } \mathbf{V}_{\text {ro }}^{r}=\frac{d \boldsymbol{\Phi}_{s}^{r}}{d t} .
$$

It is seen from (8) that the rotor voltage is jointly defined by two components: the electromagnetic force (EMF) induced by the stator-flux space vector; and the voltage drops across $R_{r}$ and $L_{\sigma}$, as shown in Fig. 4(b). Parameters $R_{r}$ and $L_{\sigma}$ are usually very small; therefore, the first term in (8) can be neglected as compared to the induced EMF, i.e., $\mathbf{V}_{r}^{r} \approx \mathbf{V}_{\text {ro }}^{r}$ [28], [29].

Under normal operation conditions, the stator-flux space vector rotates at the slip frequency with respect to the rotor winding. Therefore, the EMF induced in the rotor winding can be calculated by

$$
\mathbf{V}_{\mathrm{ro}}^{r}=\frac{d \boldsymbol{\Phi}_{s}^{r}}{d t}=j s \omega_{s} \boldsymbol{\Phi}_{s}^{r} .
$$

According to (9), the induced EMF is proportional to the machine slip and rotates slowly with the frequency of $s \omega_{s}$. The DFIG technology is to be used in applications with limited slip range (typically less than $\pm 0.3 \mathrm{pu}$ ); thus, the rotor voltage will be equal to a reduced fraction of the stator voltage (the turn ratio between the stator and rotor windings is assumed to be equal to one). This can be used to design the rotor side converter (RSC), and calculate, with some safety margin, the maximum voltage needed at the converter output. The nominal output voltage of the RSC must be large enough to dominate the induced EMF, and in turn, be capable of controlling the rotor current through the adopted field-oriented vector control scheme.

Now, assume that a symmetrical three-phase fault occurs in the grid and the stator voltage drops to zero. In such an extreme case, the stator-flux space vector becomes fixed with respect to the stationary frame, or in other words, it rotates at the speed of $\omega_{r}$ in the rotor winding. This would generate a transient EMF component with the initial value of $\left|\boldsymbol{\Phi}_{s 0}\right|=\omega_{r} \boldsymbol{\Phi}_{s}=(1-$ $s) \omega_{s} \boldsymbol{\Phi}_{s}$ in the rotor winding. This natural response is needed just after the fault occurrence instant to avoid sudden changes in the stator-flux trajectory, then, it exponentially decays to zero with a speed proportional to the stator time constant $\left(\tau_{s}=\right.$ $L_{m} / R_{s}$ ) [28]. Despite the decaying nature, the initial value of the natural EMF component can be severely large because it is proportional to $(1-s)$. Therefore, it is very likely that the natural EMF exceeds the voltage rating of the rotor-side converter just after the fault occurrence. As a result, the controllability of the converter will be lost temporarily and severe overvoltages will appear in the rotor winding. Referring to Fig. 4(b), these transient overvoltages are imposed on the impedance formed by $R_{r}+j \omega_{r} L_{\sigma}$. Since the impedance of the rotor winding at this frequency is small (typically less than $0.5 \mathrm{pu}$ ), transient overcurrents with magnified amplitudes can flow in the rotor winding. This can easily destroy the semiconductor switches in the RSC if no protection scheme is incorporated.

Similar comments can be made for partial voltage sags with depth $p$. In this case, the stator-forced flux, imposed by the grid voltage, suddenly drops to $(1-p) \boldsymbol{\Phi}_{s}$ at the fault occurrence instant. However, the stator flux is a state variable that cannot

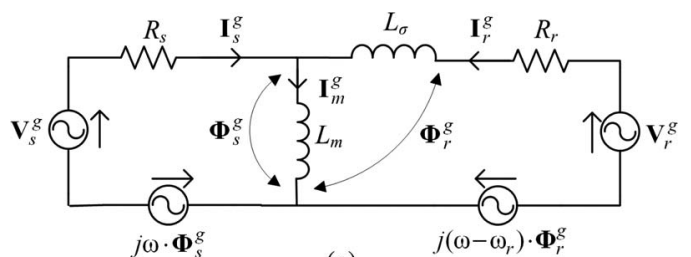

(a)

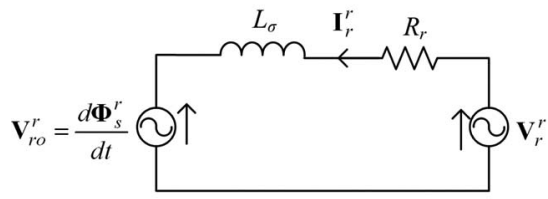

(b)

Fig. 4. (a) " $\Gamma$-form" equivalent circuit of the machine. (b) Equivalent circuit of the machine viewed in the rotor frame.

instantaneously change. Thus, a natural component with the frequency of $(1-s) \omega_{s}$ must be incorporated to guarantee the flux continuity at the fault start and clearance instants.

Under asymmetrical grid faults, a negative-sequence component will be added to the three-phase stator-voltage waveform. This voltage sequence $\left(\mathbf{V}_{s_{-}}\right)$generates a flux component rotating clockwise at the speed of $(2-s) \omega_{s}$ with respect to the rotor winding [29]. The corresponding EMF is equal to $j(2-$ s) $\omega_{s} \boldsymbol{\Phi}_{s-}$ that will be imposed on the rotor winding impedance of $R_{r}+j(2-s) \omega_{s} L_{\sigma}$. This generates larger current ripples at the frequency of $(2-s) f_{s}$ in the rotor winding. Moreover, a natural flux component must be incorporated to insure the continuity of the stator-flux trajectory at the beginning and the end of the fault. The initial value of the natural flux component depends on depth and type of the sag as well as the phase-angle jump value and the initial point-on-wave instant. The highest natural flux response would appear when the positive and negative components of the stator flux are aligned in the opposite directions. In such an extreme case, the stator-forced flux, which is equal to the vector summation of positive- and negative-sequence components, has the minimum possible amplitude just after the sag instant. Thus, the largest value of the natural flux will be needed to avoid the discontinuity in the stator-flux trajectory. On the other hand, if the positive and negative sequences of the stator flux are aligned in the same direction at the fault instant, the forced-flux space vectors can be identical before and after the fault and no natural response will be observed in the flux trajectory.

\section{EFFECTS OF Voltage SAGS ON DFIG}

In this section, extensive simulation studies are carried out to examine the operation of DFIG under different types of voltage sags. It will be shown that symmetrical and asymmetrical grid faults affect the DFIG in different ways and large phase-angle jumps has large detrimental impacts on the DFIG-based wind turbines. Moreover, the effects of initial point-on-wave instant and the voltage-recovery parameters will be examined.

The simulation analysis is conducted using MATLAB/Simulink. Fig. 5 shows the schematic diagram of the simulated network with the parameters given in the Appendix. The stator-flux-oriented vector controller is adopted in the RSC to 


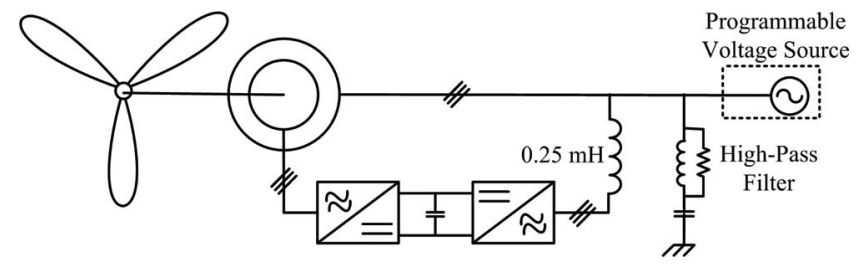

Fig. 5. Schematic circuit diagram of the simulated network.

control the active and reactive powers of the DFIG, while the grid-side converter (GSC) is aimed to keep the dc-link voltage constant. This vector control scheme has been comprehensively discussed in [26]. Also, a programmable voltage source is implemented to simulate various sag conditions that can be experienced at the generator terminals.

\section{A. Symmetrical Faults and Voltage-Recovery Process}

The DFIG operation under symmetrical three-phase faults is tested by imposing a 60\% type-A sag with zero phase-angle jump (Point $B_{1}$ in Fig. 3). The fault current angle has been set to $\psi=80^{\circ}$ and the machine rotates with $\omega_{r}=1.2 \mathrm{pu}$. It is known that the most critical electrical parameters during sag conditions are the stator voltage, rotor current, and dc-link voltage [13]-[16]. Fig. 6 shows the simulation results with three possibilities of the sag recovery. The stator-voltage waveforms are shown in Fig. 6 (a)-(c) and zoomed at the voltage-recovery instant in Fig. 6 (d)-(e). The main observations are as follows.

1) Fig. 6 (g)-(i): The fault causes a large transient overcurrent of $1.75 \mathrm{pu}$ in the rotor winding at $t=0.1 \mathrm{sec}$ regardless of the recovery type. This overshoot is originated from the natural response of the stator flux. The corresponding EMF component is fixed with respect to the stationary frame; thus, it generates a current component with $f=1.2$ $\mathrm{pu}=60 \mathrm{~Hz}$ in the rotor winding. As the natural EMF decays to zero after $0.1 \mathrm{~s}$, the RSC regains the controllability of the current in the rotor winding and regulates it back to the prefault command value. Note that there is no steadystate ripple during the fault because the resulting voltage sag (type A) does not include any negative-sequence component.

2) Fig. 6 (j)-(1): Large overcurrents in the rotor winding lead to the sudden increase of the active power injected from the RSC into the dc-link capacitor. However, the partially scaled GSC does not have enough capacity to immediately transfer the superfluous power from the capacitor to the grid. As a result, the dc-link voltage temporarily increases to $1.2 \mathrm{pu}$. Note that the GSC capability to transfer the active power has been further decreased during the fault because the grid voltage has dropped by $40 \%$ [16].

3) Fig. 6 (g)-(l): The overshoots of the rotor current and dclink voltage at the fault clearance instant vary depending on the voltage-recovery type. The most severe transients will be observed if the breakers are assumed to clear the three-phase fault in one step (unrealistic type $\mathrm{A}_{0}$ ). However, it is worth noting that the overshoots at $t_{f 1}$ are still smaller than the initial point-on-wave instant $\left(t_{i}\right)$ as the GSC capacity to transfer the superfluous power will in- crease after the fault clearance instant due to the full availability of the grid voltage.

4) Fig. 6 (g)-(l): The voltage-recovery process will generate smaller overshoots if the operational contrarians of the circuit breakers are taken into account and three-phase faults are considered to be cleared at the natural zero-crossing points of the phase currents. By comparing the simulation results for type $A_{0}$ with types $A_{1}$ and $A_{3}$, it is clear that the rotor current and dc-link voltage overshoots decrease from 1.7 to $1.1 \mathrm{pu}$ and from 1.15 to $1.03 \mathrm{pu}$, respectively. These observations can be justified by analyzing the sequence components of the stator flux during the voltagerecovery process. For type $\mathrm{A}_{0}$, the full voltage recovery will take place in one step at the final point-on-wave $\left(t_{f 1}\right)$. This would generate a large sudden change of $0.4 \mathrm{pu}$ in the stator-forced flux. Consequently, a large natural flux component will be required to provide the continuity in the stator-flux trajectory and large overshoots will appear in the rotor winding. However, for types $A_{1}$ and $A_{3}$, the three-phase fault will be cleared in two and three consecutive steps, respectively. According to Table II (rows 2 and 4), this means that the type $A_{1}$ develops to type $C_{a}$, and the type $\mathrm{A}_{3}$ develops to type $\mathrm{E}_{2 a}$, and then type $\mathrm{B}_{b}$ before the full recovery. Therefore, the forced component of the stator flux gradually changes in two or three consecutive steps and smaller natural flux components are required to avoid the stator-flux discontinuity at each step.

Fig. 7 shows the influence of the fault current angle on the dc-link voltage during the voltage-recovery process. It is clear that the overshoot in the dc-link voltage increases by $10 \%$ when the fault current angle changes from $85^{\circ}$ to $45^{\circ}$. Therefore, it can be concluded that more severe voltage-recovery conditions will be experienced in the DFIG-based wind farms connected to distribution systems or located offshore. It is also worth noting that the dc-link voltage overshoot under the worst scenario $(\psi=$ $45^{\circ}$ ) is still smaller than the unrealistic voltage-recovery overshoot of $1.15 \mathrm{pu}$ (experienced in type $\mathrm{A}_{0}$ ). Similar observations have been made for other types of voltage sags with different possibilities of voltage recovery.

\section{B. Asymmetrical Faults and Phase-Angle Jump}

The DFIG operation under asymmetrical faults is examined by imposing a $60 \%$ type-C voltage sag at the wind generator terminals. Simulation results, presented in Fig. 8, show the effects of the initial point-on-wave instant and phase-angle jump on the DFIG transient response. For the theoretical analysis of simulation results, the grid voltage is decomposed into the positiveand negative-sequence components, given in Table III. The main observations are as follows.

1) Fig. 8(a), (d), and (g): If the sag type $\mathrm{C}$ occurs at $t_{i}=\mathrm{T}=$ $20 \mathrm{msec}$, the positive- and negative-sequence components of the grid voltage are aligned in the same direction (Point $\mathrm{B}_{1}$ in Table III, $\mathbf{V}_{+}=0.8\left\llcorner 0^{\circ}\right.$ and $\mathbf{V}_{-}=0.2\left\llcorner 0^{\circ}\right.$ ). Consequently, the forced flux component will be equal to 1.0 pu just after the fault instant and no natural flux component will be required to provide the stator-flux continuity. 
(a)

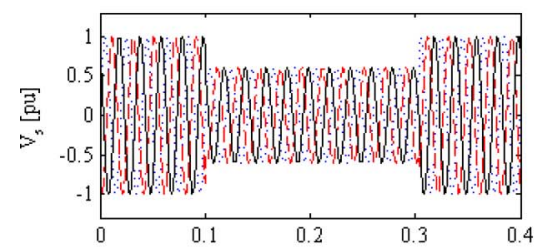

(d)

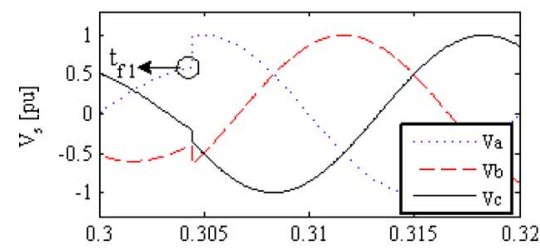

(g)

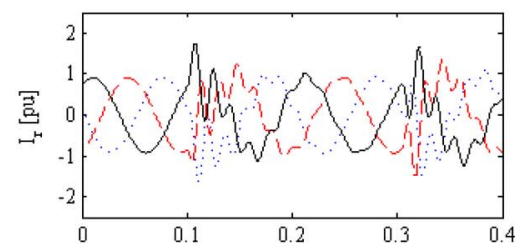

(j)

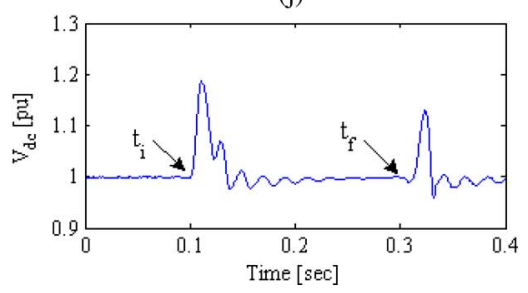

(b)

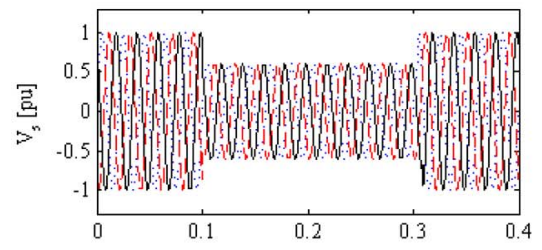

(e)

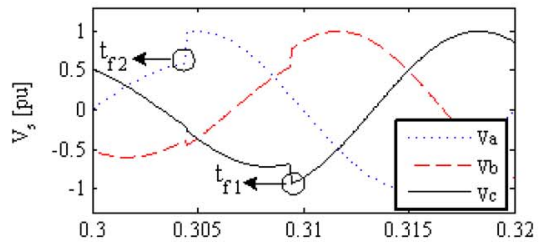

(h)

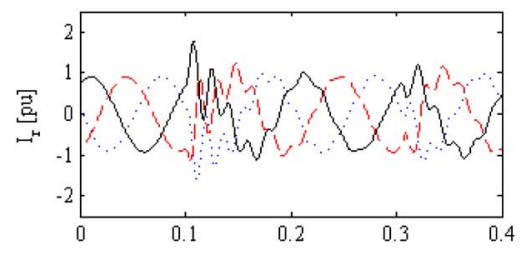

(k)

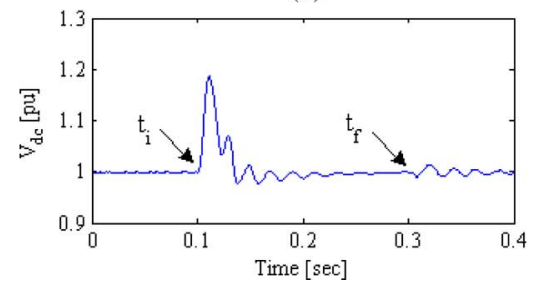

(c)

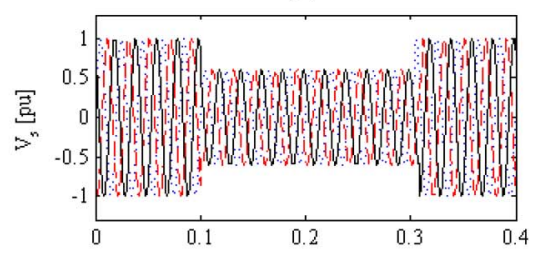

(f)

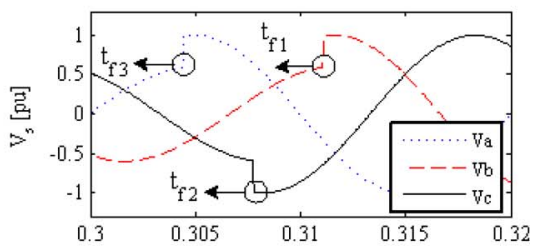

(i)

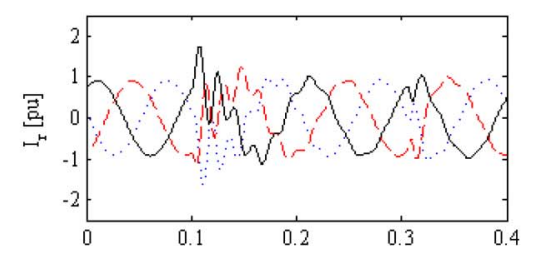

(1)

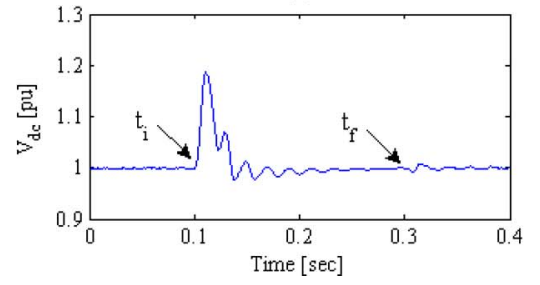

Fig. 6. Simulation results for three-phase faults (type A) with different possibilities of the voltage recovery. (a) Sag Type $A_{0}$ - Stator voltage. (b) Sag Type $A_{1}$ Stator voltage. (c) Sag Type $A_{3}$ - Stator voltage. (d) Sag Type $A_{0}-$ Stator voltage (zoomed around $t_{f l}$ ). (e) Sag Type $A_{1}-$ Stator voltage (zoomed around $t_{f}$ ). (f) Sag Type $A_{3}$ - Stator voltage (zoomed around $t_{f}$ ). (g) Sag Type $A_{0}$ - Rotor current. (h) Sag Type A 1 - Rotor current. (i) Sag Type $A_{3}$ - Rotor current. (j) Sag Type $A_{0}$ - Dc-link voltage. (k) Sag Type Sag Type $A_{1}$ - Dc-link voltage. (1) Sat Type $A_{3}$ - Dc-link voltage.

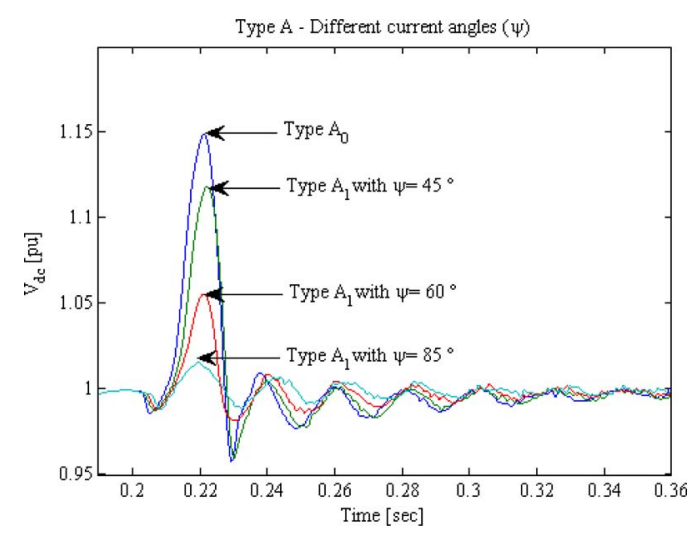

Fig. 7. Influence of the fault current angle $\psi$ on the dc-link voltage during the voltage-recovery process.

Likewise, there is no transient overshoot in the rotor current or dc-link voltage. However, the presence of the negative sequence in the stator voltage generates large current ripples in the rotor winding, with the peak-to-peak magnitude of $0.6 \mathrm{pu}$ and the frequency of $(2-s) f_{s}=110 \mathrm{~Hz}$. Similar double-frequency oscillations $( \pm 2.3 \%)$ can be observed in the dc-link voltage.
2) Fig. 8(j): Under normal operation conditions, the statorflux space vector traces a circular trajectory of $1.0 \mathrm{pu}$ radius, imposed by the grid voltage. Then, as the fault takes place, the flux trajectory changes to an ellipse without any transients. The major axis of the ellipse corresponds to the instants that positive- and negative-sequence components are aligned in the same direction, whereas the minor axis appears when they are aligned in opposite directions.

3) Fig. 8(b), (e), and (h): The relative rotation speed of the positive- and negative-sequence components of the grid voltage is equal to $2 \omega_{s}$. Therefore, if the sag occurs at $t_{i}=$ $\mathrm{T} / 4=5 \mathrm{msec}$, the positive- and negative-sequence components of the grid voltage will be aligned in the opposite directions $\left(\mathbf{V}_{+}=0.8\left\llcorner 90^{\circ}\right.\right.$ and $\mathbf{V}_{-}=0.2\left\llcorner-90^{\circ}\right)$. In such an extreme case, the stator-forced flux has the minimum possible value just after the sag (equal to $0.6 \mathrm{~L}$ $90^{\circ}$ ) and the large natural flux response of $0.4 \mathrm{pu}$ will be needed to avoid discontinuity in the stator-flux trajectory. This will generate large transient overshoots of 2.0 and $1.2 \mathrm{pu}$ in the rotor current and dc-link voltage, respectively. The natural response decays after $0.1 \mathrm{sec}$, whereas the negative-sequence oscillations remain unsuppressed during the fault period. 
(a)

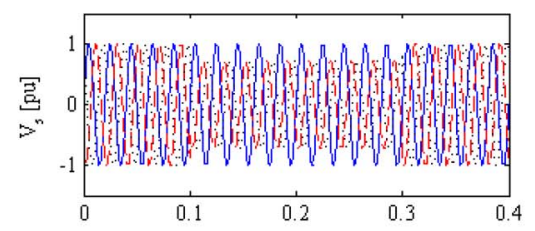

(d)

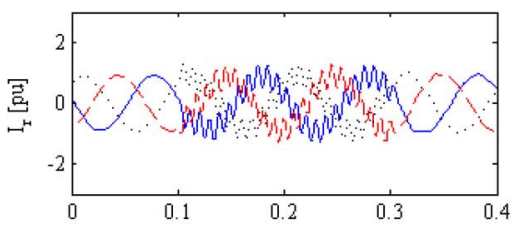

(g)

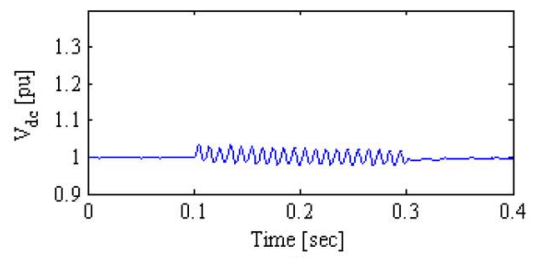

(j)

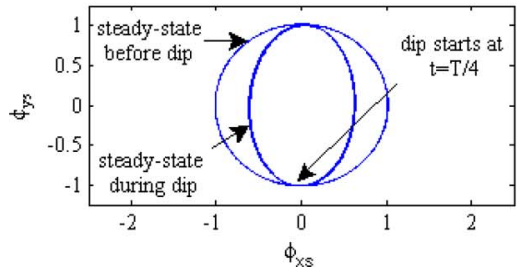

(b)

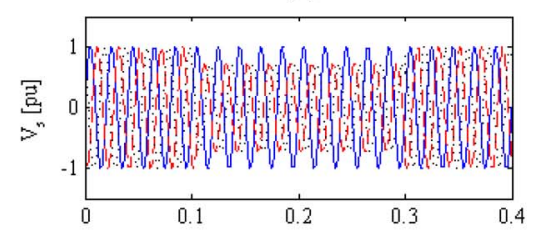

(e)

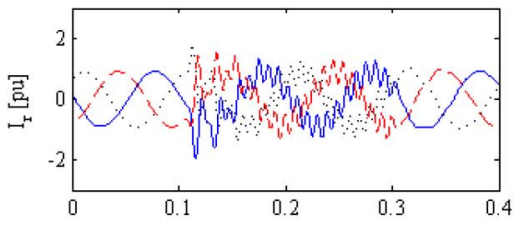

(h)

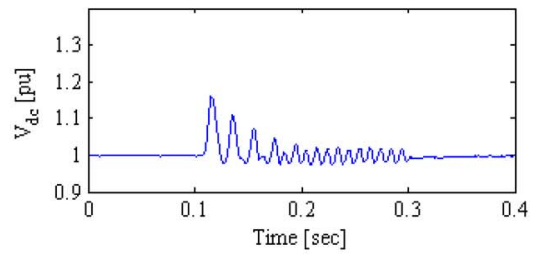

(k)

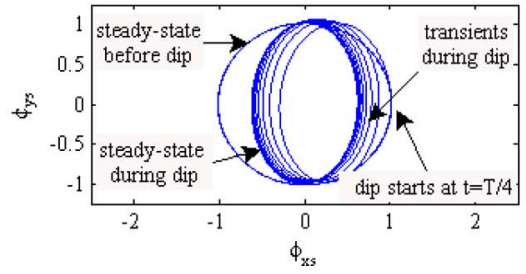

(c)

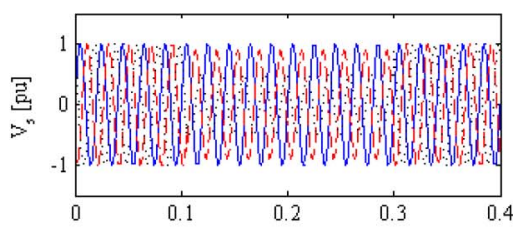

(f)

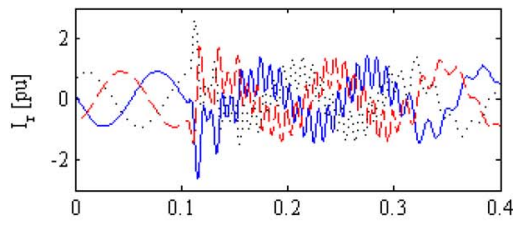

(i)

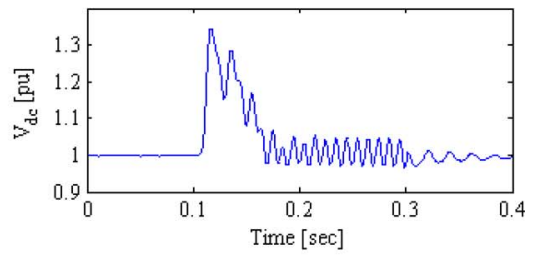

(1)

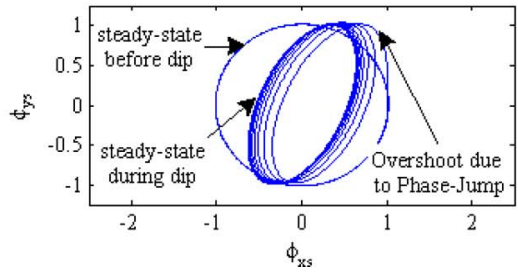

Fig. 8. Simulation results for $60 \%$ type-C voltage sag with different initial point-on-wave instants, without and with phase-angle jump. (a) Sag Type $\mathrm{C}_{1}$ and $\mathrm{t}_{i}=$ 0. (b) Sag Type $C_{1}$ and $t_{1}=T / 4$. (c) Sag Type $C_{1}$ and $t_{1}=T / 4$ (with Phase-angle jump). (d) Sag Type $C_{1}$ and $t_{i}=0$. (e) Sag Type $C_{1}$ and $t_{1}=T / 4$. (f) Sag Type $\mathrm{C}_{1}$ and $\mathrm{t}_{1}=\mathrm{T} / 4$ (with Phase-angle jump). (g) Sag Type $\mathrm{C}_{1}$ and $\mathrm{t}_{i}=0$. (h) Sag Type $\mathrm{C}_{1}$ and $\mathrm{t}_{1}=\mathrm{T} / 4$. (i) Sag Type $\mathrm{C}_{1}$ and $\mathrm{t}_{1}=\mathrm{T} / 4$ (with Phase-angle jump). (j) Sag Type $C_{1}$ and $t_{i}=0$. (k) Sag Type $C_{1}$ and $t_{1}=T / 4$. (l) Sag Type $C_{1}$ and $t_{1}=T / 4$ (with Phase-angle jump).

TABLE III

DECOMPOSITION OF THE GRID VOLTAGE INTO THE POSITIVE- AND NeGATIVE-SEQUENCE COMPONENTS FOR DifFERENT SAG TyPES

\begin{tabular}{|c||c|c||c|c||}
\hline \multirow{2}{*}{ Sag Type } & \multicolumn{2}{c||}{ Point $\mathrm{B}_{1}\left(0.6\left\llcorner 0^{\circ}\right)\right.$} & \multicolumn{2}{c||}{ Point $\mathrm{B}_{3}\left(0.6\left\llcorner-31^{\circ}\right)\right.$} \\
\cline { 2 - 5 } & $\mathbf{V}_{+}$ & $\mathbf{V}_{-}$ & $\mathbf{V}_{+}$ & $\mathbf{V}_{-}$ \\
\hline \hline \multirow{2}{*}{$\mathrm{A}$} & $0.6\llcorner 0$ & 0.0 & $0.6\llcorner-31$ & 0.0 \\
\hline C $^{*}$ & $0.85\llcorner 0$ & $0.13\llcorner 0$ & $0.84\llcorner-7$ & $0.19\llcorner 32$ \\
\hline C & $0.8\llcorner 0$ & $0.2\llcorner 0$ & $0.77\llcorner-12$ & $0.29\llcorner 33$ \\
\hline D & $0.8\llcorner 0$ & $0.2\llcorner-180$ & $0.77\llcorner-12$ & $0.29\llcorner-147$ \\
\hline F & $0.73\llcorner 0$ & $0.13\llcorner-180$ & $0.71\llcorner-17$ & $0.19\llcorner-147$ \\
\hline G & $0.73\llcorner 0$ & $0.13\llcorner 0$ & $0.71\llcorner-17$ & $0.19\llcorner 33$ \\
\hline
\end{tabular}

4) Fig. 8(k): The natural flux response of 0.4 pu forces the stator-flux trajectory to be positioned away from the origin just after the fault instant. The natural flux component finally decays to zero with a speed proportional to the stator winding time constant and the stator-flux elliptic trajectory will be centered again at the origin.

5) Fig. 8(c), (f), and (i): For offshore wind farms, the $60 \%$ voltage sag will be associated with a phase-angle jump of $-31^{\circ}$, i.e., $\mathbf{V}_{\text {sag }}=0.6\left\llcorner-31^{\circ}\right.$. This sag condition leads to the positive- and negative-sequence components of $\mathbf{V}_{+}=0.77\left\llcorner-12^{\circ}\right.$ and $\mathbf{V}_{-}=0.29\left\llcorner 33^{\circ}\right.$ for the type-C sag starting at $t_{i}=0 \mathrm{sec}$ (refer to Point $\mathrm{B}_{3}$ in Table II). Accordingly, if the sag occurs at $t_{i}=\mathrm{T} / 4=5 \mathrm{msec}$, the sequence components of the grid voltage just after the fault instant are equal to $\mathbf{V}_{+}=0.77\left\llcorner 78^{\circ}\right.$ and $\mathbf{V}_{-}=$ $0.29\left\llcorner-57^{\circ}\right.$; thus, the forced flux will be equal to 0.6\llcorner $58^{\circ}$ and a natural response of $0.68\left\llcorner-37^{\circ}\right.$ is required in the stator-flux response. This would generate very large transient overshoots of 2.7 and 1.35 pu in the rotor current and dc-link voltage, respectively. In addition, the doublefrequency ripples in the rotor current and dc-link voltage will rise to $1.0 \mathrm{pu}$ and $\pm 4.2 \%$, respectively, due to the increase in the negative-sequence component of the grid voltage.

6) Fig. 8(1): Very large natural flux response of 0.68 pu has been manifested in the stator-flux trajectory by the large overshoot observed just after the fault instant. Also, the axes of elliptic trajectory have been tilted by $45^{\circ}$ since the positive and negative sequences of the grid voltage are in $45^{\circ}$ phase difference for Point $B_{3}$.

\section{InFluence of SAg PARAmeters on the TRANSIENT RESPONSE OF DIFG}

In this section, the influence of the initial point-on-wave instant, sag depth, and network impedance angle on the transient 
(a)

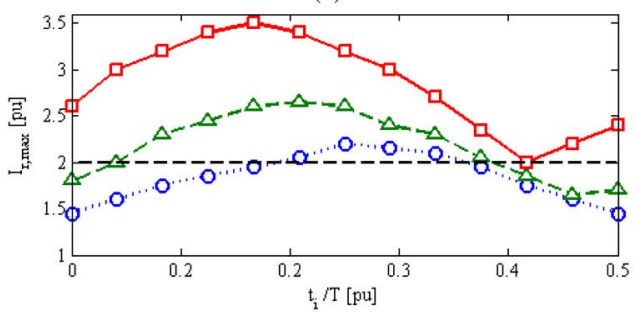

(c)

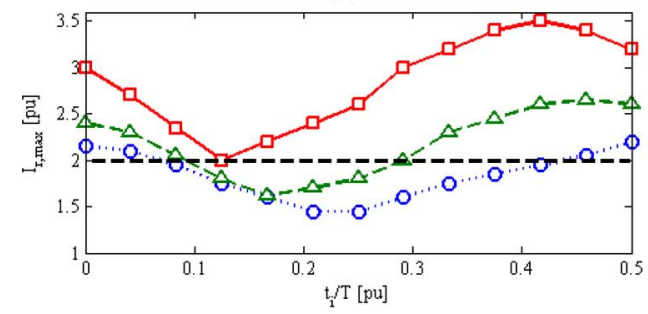

(b)

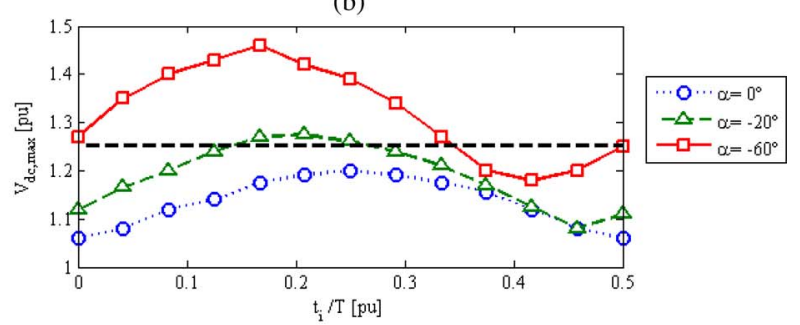

(d)

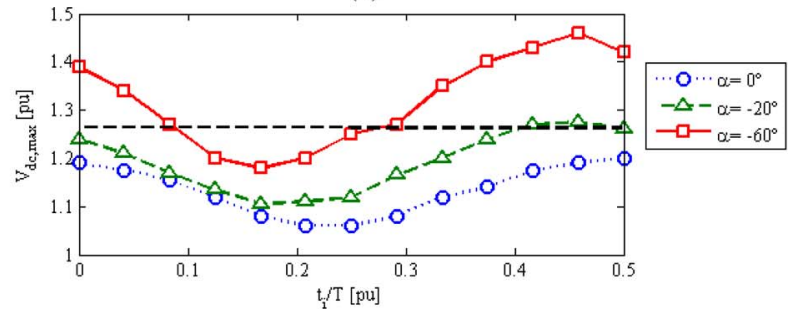

Fig. 9. Influence of the initial point-on-wave instant on the transient response of DFIG-based wind turbines subjected to phase-to-phase faults, i.e., sag types C and D (typical safety margins are shown with dashed horizontal lines). (a) Sage Type C. (b) Sage Type C. (c) Sage Type D. (d) Sage Type D.

TABLE IV

SUMMARIZED SIMULATION RESULTS FOR DIFFERENT TYPES OF FAULTS

\begin{tabular}{|c|c|c|c|c|c|c|c|c|c|}
\hline \multirow{2}{*}{ Fault (Sag Type) } & \multicolumn{3}{|c|}{$\alpha=0^{\circ}$} & \multicolumn{3}{|c|}{$\alpha=-20^{\circ}$} & \multicolumn{3}{|c|}{$\alpha=-60^{\circ}$} \\
\hline & $\theta_{\text {peak }}\left({ }^{\circ}\right)$ & $\mathrm{I}_{\mathrm{r}, \mathrm{p}}$ & $\mathrm{V}_{\mathrm{dc}, \mathrm{p}}$ & $\theta_{\text {peak }}\left({ }^{\circ}\right)$ & $I_{r, p e a k}$ & $\mathrm{~V}_{\mathrm{dc}, \text { peak }}$ & $\theta_{\text {peak }}\left({ }^{\circ}\right)$ & $I_{r, p e a k}$ & $\mathrm{~V}_{\text {dc,peak }}$ \\
\hline$\Phi-g\left(C^{*} \& D^{*}\right)$ & $90 \& 180$ & 1.75 & 1.13 & $83 \& 173$ & 1.93 & 1.16 & $77 \& 167$ & 2.53 & $1.56^{*}$ \\
\hline$\Phi-\Phi(\mathrm{C} \& \mathrm{D})$ & $90 \& 180$ & 2.2 & 1.21 & $84 \& 174$ & 2.65 & 1.28 & $80 \& 170$ & $3.5 * *$ & 1.46 \\
\hline $2 \Phi-g(G \& F)$ & $90 \& 180$ & 2.15 & 1.2 & $85 \& 175$ & 2.45 & 1.26 & $82 \& 172$ & 3.25 & 1.41 \\
\hline $3 \Phi(\mathrm{A})$ & - & 1.9 & 1.23 & - & 2.1 & 1.3 & - & 2.95 & 1.61 \\
\hline
\end{tabular}

* Most severe case in terms of the overshoot in the dc-link voltage.

** Most severe case in terms of the overshoot in the rotor current.

response of DFIG will be investigated. The parameters of interest for this study are the peak values of the rotor current and dc-link voltage, defined in per unit as follows:

$$
\begin{aligned}
I_{r, \text { peak }} & =\frac{\max \left\{\left|I_{r a}(t)\right|,\left|I_{r b}(t)\right|,\left|I_{r c}(t)\right|\right\}}{I_{r, \text { base }}} \\
V_{\text {dc,peak }} & =\frac{\max \left\{\left|V_{\mathrm{dc}}(t)\right|\right\}}{V_{\mathrm{dc}, \text { base }}} .
\end{aligned}
$$

To examine the influence of initial point-on-wave instant, the DFIG system is subjected to various types of voltage sags with $60 \%$ remnant voltage and different impedance angles. It was observed that the peaks in the rotor current and dc-link voltage have periodic behavior in each half cycle of the fundamental period. Simulation results also show that the initial point-onwave instant has no influence on the peak values for three-phase faults (type A) because there is no associated negative-sequence component. In contrast, the effect of this parameter is enormous for asymmetrical faults. Fig. 9 displays the peak values of the rotor current and dc-link voltage versus the initial point-onwave instant for $60 \%$ types $\mathrm{C}$ and $\mathrm{D}$ voltage sags. Typical safety margins are also shown in Fig. 9, equal to 2.0 and 1.25 pu for $I_{r}$ and $V_{\mathrm{dc}}$, respectively [13]. Comprehensive simulation results for sag types A, C* , D* C, D, G, and F have been summarized in Table IV. The main observations are as follows.
1) The maximum peaks for types $C^{*}, C$, and $G$ with no phaseangle jump take place at $t_{i}=\mathrm{T} / 4 \sec \left(\theta_{i}=90^{\circ}\right)$, whereas the highest peaks for types $\mathrm{D} *, \mathrm{D}$, and $\mathrm{F}$ occurs at the initial point-on-wave instant equal to zero (Table IV, second column). Theses figures will change when the sag is associated with a phase-angle jump. Generally, the most unfavourable initial point-on-wave corresponds to the instant that the positive- and negative-sequence components of the grid voltage are aligned in opposite directions, e.g., $\theta_{\text {peak }}=77^{\circ}$ and $167^{\circ}$ for sag types $\mathrm{C}^{*}$ and $\mathrm{D}^{*}$ with $\alpha=$ $-60^{\circ}$, respectively.

2) The overshoots in the rotor current and dc-link voltage will significantly increase and exceed the safety limits of the DFIG system if the sag is associated with a large phase-angle jump. For example, if the impedance angle changes from 0 to $-60^{\circ}$, the overshoots in $I_{r}$ and $V_{\mathrm{dc}}$ will increase by $45 \%-60 \%$ and $20 \%-40 \%$, respectively. This observation is consistent with the increase of the negative-sequence component of the grid voltage when voltage sags are associated with phase-angle jump (refer to Table III). With large phase-angle jumps, the minimum possible value of the forced flux (the difference between positive and negative components) reduces significantly and accordingly, larger natural flux responses will be needed to avoid the flux discontinuity. Therefore, 
(a)

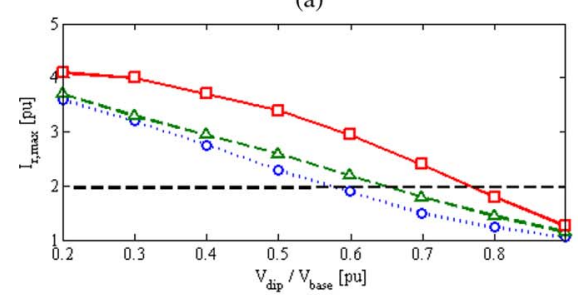

(c)

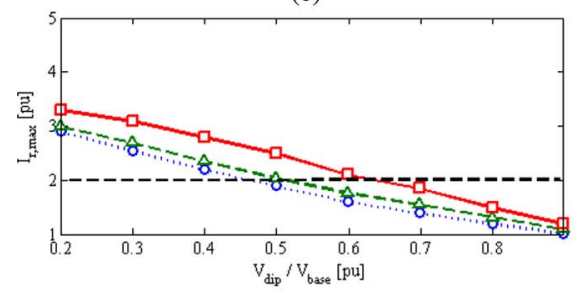

(e)

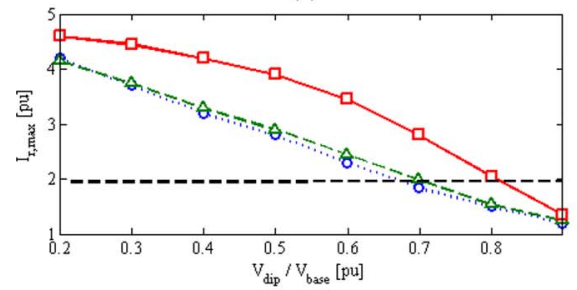

(g)

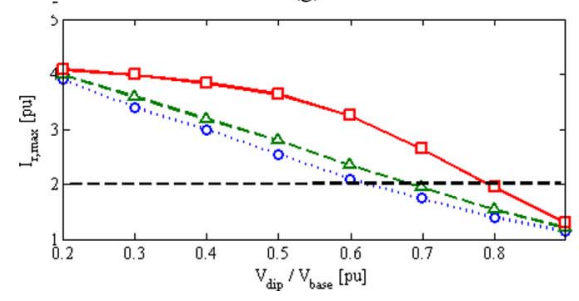

(b)

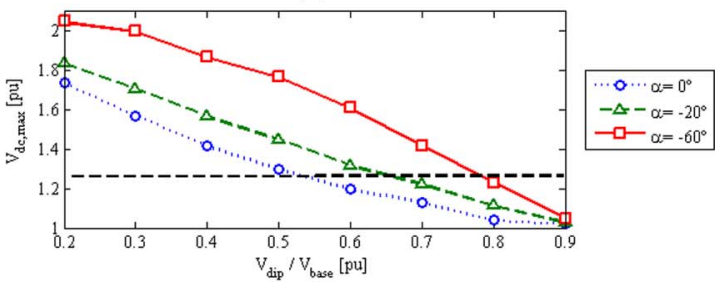

(d)

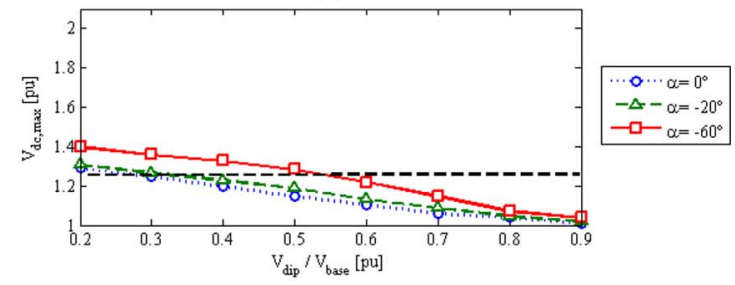

(f)

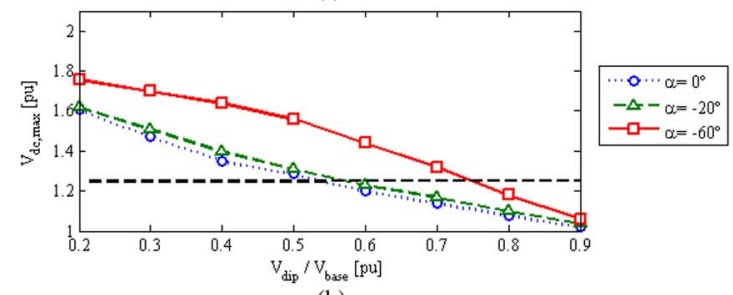

(h)

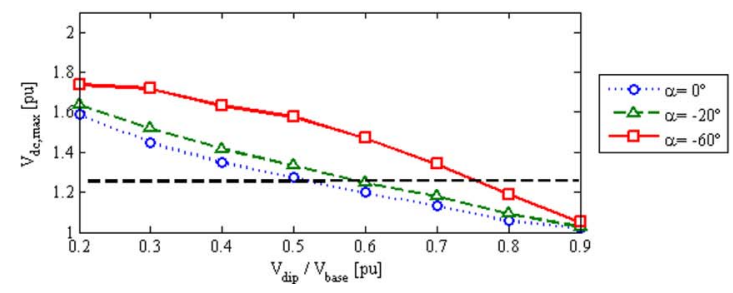

Fig. 10. Influence of the sag depth on the transient response of DFIG-based wind turbine subjected to different types of faults (typical safety margins are shown with dashed horizontal lines). (a) Three-phase fault (Type A). (b) Three-phase fault (Type A). (c) Single-phase-to-ground fault (Types $\mathrm{C}^{*}$ and $\mathrm{D}^{*}$ ). (d) Single-phase-to-ground fault (Types $\mathrm{C}^{*}$ and $\mathrm{D}^{*}$ ). (e) Phase-to-phase fault (Types C and D). (f) Phase-to-phase fault (Types C and D). (g) Two-phase-to-ground fault (Types F and G). (h) Two-phase-to-ground fault (Types F and G).

it is concluded that large phase-angle jumps associated with voltage sag have significant detrimental impacts on transient responses of DFIG-based wind turbines.

3) Under identical sag conditions, the largest overshoot of the rotor current is observed under phase-to-phase faults, i.e., sag types $\mathrm{C}$ and $\mathrm{D}$. The rotor current under fault conditions is equal to the superposition of the positive, negative, and zero-sequence components. Phase-to-phase faults generate the highest negative-sequence components in the grid voltage; therefore, the largest initial overshoot will be experienced in the rotor current in types $\mathrm{C}$ and $\mathrm{D}$, as compared to other sag types (refer to Table III). On the other hand, the overshoot of the dc-link voltage is directly proportional to the amplitude of the positive sequence of the grid voltage [16]. According to Table III, type-A sags give the lowest positive voltage sequence values; thus, the largest overshoot in the dc-link voltage will be expected under three-phase faults.

Finally, to study the impact of sag depth on the DFIG transient behavior, the most severe initial point-on-wave instants that produce the highest peaks in the rotor current and dc-link voltage have been considered for various sag conditions. Fig. 10 shows an almost linear relationship between the sag depth and peaks of the rotor current or dc-link voltage, i.e., higher peaks will be observed as the depth increases. These simulation results also confirm the validity of the observations made in the last sections: large phase-angle jumps have significant detrimental impacts on the DFIG response, and the most severe overshoots in the rotor current and dc-link voltage will be experienced for phase-to-phase and three-phase faults, respectively.

\section{CONCLUSION}

A new analysis into the transient behavior of DFIG-based wind turbines under various (a)symmetrical fault conditions is presented. For the first time, the impacts of phase-angle jump, voltage-recovery process, and various sag parameters (e.g., depth, type, instant on point-of-wave, and impedance angle) are examined. Extensive simulation studies are carried out and supported by theoretical justifications. The main conclusion is summarized as follows.

1) For symmetrical sags (type A), the natural response of the stator flux generates large transient overshoots in the rotor current and dc-link voltage at the beginning and the 
end of the three-phase faults. However, if the operational constraints of the circuit breakers are taken into account, the full voltage recovery will take place in two or three consecutive steps and smaller overshoots will be experienced at the fault clearance instant (see Fig. 6). For wind generators connected to the distribution system or located offshore, overshoots during the recovery process are expected to increase as the fault current angle decreases (see Fig. 7).

2) For asymmetrical sags (types B to G), steady-state oscillations as well as transient overshoots are observed in the rotor current and the dc-link voltage. The most unfavorable initial point-on-wave instants, with the largest overshoots, have been identified for various sag types. This corresponds to the moment that the positive- and negative-sequence components are aligned in the opposite directions (refer to Figs. 8-and 9, and Table IV).

3) The negative-sequence component of the grid voltage increases when the voltage sag is associated with large phase-angle jumps. This has significant detrimental impacts on wind turbines located offshore, since the transient overshoots in the rotor current and dc-link voltage can increase by $45 \%-60 \%$ and $20 \%-40 \%$, respectively (see Figs. 8 and 9, and Table IV).

4) Table IV shows that under identical sag conditions, the largest overshoots in the dc-link voltage are experienced for three-phase faults (type A), while the highest peaks for the rotor current are observed under phase-to-phase faults (types C and D). Also, a linear relationship is obtained between the sag depth and peaks of the rotor current or dc-link voltage, i.e., higher peaks will be expected as the depth increases (see Fig. 10).

Finally, it is hoped that the simulation results and theoretical discussions presented in this paper can help researchers, designers, and engineers to develop improved control schemes for DFIG-based wind turbines to ride through the grid faults and comply with the new grid code requirements.

\section{APPENDIX}

Phasor diagrams for asymmetrical sag types ("B" to "G") and parameters for the simulated DFIG are given in Table V and VI, respectively.

TABLE V

Phasor Diagrams of Various Voltage Sag Types: Three-Phase Voltages BEFore (DOTTED) AND DURING SAG (SOLID) ARE DisPLAYED

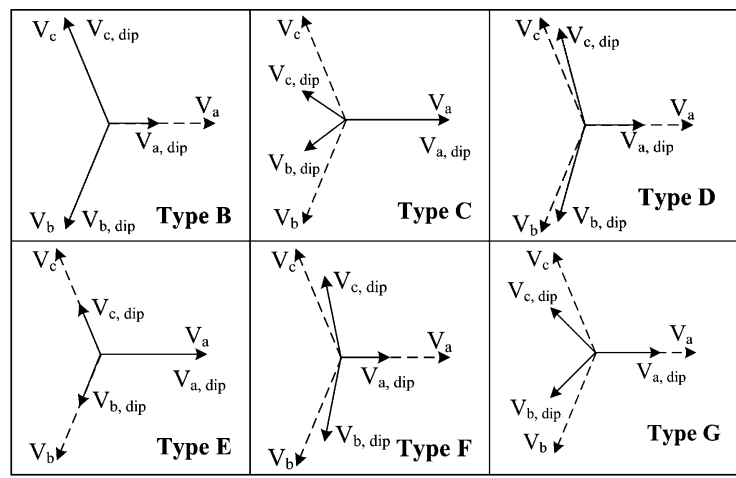

TABLE VI

PARAMETERS OF THE SIMULATED DFIG

\begin{tabular}{|c|c|}
\hline Rated Power & $1.75 \mathrm{MVA}$ \\
\hline Stator Voltage/Frequency & $575 \mathrm{~V} / 50 \mathrm{~Hz}$ \\
\hline$R_{s} / R_{r}$ & $0.007 \mathrm{pu} / 0.005 \mathrm{pu}$ \\
\hline$L_{m} / L_{\sigma}$ & $3.2 \mathrm{pu} / 0.32 \mathrm{pu}$ \\
\hline$V_{d c}$ & $1200 \mathrm{~V}$ \\
\hline
\end{tabular}

\section{REFERENCES}

[1] T. Ackermann, Wind Power in Power Systems. Hoboken, NJ: Wiley, 2005.

[2] Z. Chen, J. M. Guerrero, and F. Blaabjerg, "A review of the state of the art of power electronics for wind turbines," IEEE Trans. Power Electron., vol. 24, no. 8, pp. 1859-1875, Aug. 2009.

[3] M. Tsili and S. Papathanassiou, "A review of grid code technical requirements for wind farms," IET Renew. Power Gener., vol. 3, no. 3, pp. 308-332, Sep. 2009.

[4] Requisitos de respuesta frente a huecos de tensión de las instalaciones eólicas, Grid Code number 12.3 of the Spanish grid operator REE (2006, Oct.) [Online]. Available at http://www.ree.es/operacion/ procedimientos_operacion.asp.

[5] V. Akhmatov, "Analysis of dynamic behavior of electric power systems with large amount of wind power," Ph.D. dissertation, Dept. of Electr. Power Eng., Tech. Univ., Copenhagen, Denmark, Apr. 2003 (available online).

[6] J. B. Ekanayake, L. Holdsworth, X. G. Wu, and N. Jenkins, "Dynamic modeling of doubly fed induction generator wind turbines," IEEE Trans. Power Electron., vol. 18, no. 2, pp. 803-809, May 2003.

[7] P. Ledesma and J. Usaola, "Doubly fed induction generator model for transient stability analysis," IEEE Trans. Energy Convers., vol. 20, no. 2, pp. 388-397, Jun. 2005.

[8] Y. Lei, A. Mullane, G. Lightbody, and R. Yacamini, "Modeling of the wind turbine with a doubly fed induction generator for grid integration studies," IEEE Trans. Energy Convers., vol. 21, no. 1, pp. 257-264, Mar. 2006.

[9] I. Erlich, J. Kretschmann, J. Fortmann, S. Mueller-Engelhardt, and H. Wrede, "Modelling of wind turbines based on doubly fed induction generators for power system stability studies," IEEE Trans. Power Syst., vol. 22, no. 3, pp. 909-919, Aug. 2007.

[10] J. Morren and S. de Haan, "Ride-through of wind turbines with doubly fed induction generator during a voltage dip," IEEE Trans. Energy Convers., vol. 20, no. 2, pp. 435-441, Jun. 2005.

[11] J. Lopez, E. Gubia, E. Olea, J. Ruiz, and L. Marroyo, "Ride through of wind turbines with doubly fed induction generator under symmetrical voltage dips," IEEE Trans. Ind. Electron., vol. 56, no. 10, pp. 4246-4254, Oct. 2009.

[12] A. Petersson, T. Thiringer, L. Harnesfors, and T. Petru, "Modeling and experimental verification of grid interaction of a DFIG wind turbine," IEEE Trans. Energy Convers., vol. 20, no. 4, pp. 878-886, Dec. 2005.

[13] D. Xiang, L. Ran, P. Tavner, and S. Yang, "Control of a doubly fed induction generator in a wind turbine during grid fault ride through," IEEE Trans. Energy Convers., vol. 21, no. 3, pp. 652-662, Sep. 2006.

[14] S. Seman, J. Niiranen, S. Kanerva, A. Arkkio, and J. Saitz, "Performance study of a double fed wind-power induction generator under network disturbances," IEEE Trans. Energy Convers., vol. 21, no. 4, pp. 883-890, Dec. 2006.

[15] O. Gomis-Bellmunt, A. Junyent-Ferre, A. Sumper, and J. Bergas-Jane, "Ride-through control of a doubly-fed induction generator under unbalanced voltage sags," IEEE Trans. Energy Convers., vol. 23, no. 4, pp. 1036-1045, Dec. 2008.

[16] J. Yao, H. Li, Y. Liao, and Z. Chen, "An improved control strategy of limiting the DC-link voltage fluctuation for a doubly fed induction wind generator," IEEE Trans. Power Electron., vol. 23, no. 3, pp. 1205-1213, May 2008

[17] Y. Zhou, P. Bauer, A. Ferreira, and J. Pierik, "Operation of grid-connected DFIG under unbalanced grid voltage condition," IEEE Trans. Energy Convers., vol. 24, no. 1, pp. 240-246, Mar. 2009.

[18] D. Santos-Martin, J. L. Rodriguez-Amenedo, and S. Arnaltes, "Providing ride-through capability to a doubly fed induction generator under unbalanced voltage dips," IEEE Trans. Power Electron., vol. 24, no. 7, pp. 1747-1775, Jul. 2009. 
[19] P. S. Flannery and G. Venkataramanan, "Unbalanced voltage sag ridethrough of a doubly fed induction generator wind turbine with series gridside converter," IEEE Trans. Ind. Appl., vol. 45, no. 5, pp. 1879-1887, Sep./Oct. 2009.

[20] F. K. A. Lima, A. Luna, P. Rodriguez, E. H. Watanabe, and F. Blaabjerg, "Rotor voltage dynamics in the doubly fed induction generator during grid faults," IEEE Trans. Power Electron., vol. 25, no. 1, pp. 118-130, Jan. 2010.

[21] M. H. J. Bollen, G. Olguin, and M. Martins, "Voltage dips at the terminals of wind power installations," Wind Energy, vol. 8, no. 3, pp. 307-318, Jul. 2005.

[22] M. H. J. Bollen, Understanding Power Quality Problems: Voltage Sags and Interruptions. New York: IEEE Press, 2000.

[23] J. Enquist, "Ride-through of offshore wind parks," M.S. thesis, Dept. of Electr. Power Eng., Chalmers University of Technology, Goteborg, Sweden, 2007 (available online).

[24] M. H. J. Bollen, "Voltage recovery after unbalanced and balanced voltage dips in three-phase systems," IEEE Trans. Power Del., vol. 18, no. 4, pp. 1376-1381, Oct. 2003.

[25] W. Leonhard, Control of Electrical Drives. London, U.K.: SpringerVerlag, 2001.

[26] R. Pena, J. C. Clare, and G. M. Asher, "Doubly fed induction generator using back-to-back PWM converters and its application to variable-speed wind-energy generation," IEEE Proc. Elect. Power Appl., vol. 143, no. 3 , pp. 231-241, May 1996.

[27] M. Mohseni, S. Islam, and M. A. S. Masoum, "Enhanced hysteresis-based current regulators in vector control of DFIG wind turbines," IEEE Trans. Power Electron., Jul. 2010.

[28] J. Lopez, P. Sanchis, X. Roboam, and L. Marroyo, "Dynamic behaviour of the doubly-fed induction generator during three-phase voltage dips," IEEE Trans Energy Convers, vol. 22, no. 3, pp. 709-717, Sep. 2007.

[29] J. Lopez, E. Gubia, P. Sanchis, X. Roboam, and L. Marroyo, "Wind turbines based on doubly fed induction generator under asymmetrical voltage dips," IEEE Trans Energy Convers, vol. 23, no. 1, pp. 321-330, Mar. 2008.

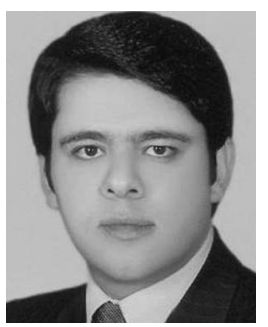

Mansour Mohseni (S'09) received the B.Sc. and M.Sc. degrees in electrical engineering from Shahid Chamran University, Ahwaz, Iran, in 2004 and 2007, respectively. $\mathrm{He}$ is currently working toward the $\mathrm{Ph} . \mathrm{D}$. degree at the Curtin University of Technology, Perth, Australia.

His research interests include wind power generation, grid integration of renewable energy systems, and power electronics.

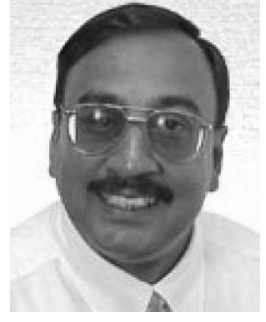

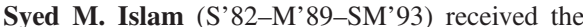
B.Sc., M.Sc., and Ph.D. degrees in electrical power engineering in 1979, 1983, and 1988, respectively, from King Fahd University of Petroleum and Minerals, Saudi Arabia.

$\mathrm{He}$ is currently the Chair Professor in Electrical Power Engineering and Head of the Department of Electrical and Computer Engineering, Curtin University of Technology, Perth, Australia. He is the author or coauthor of over 170 published technical papers in his area of expertise. His research interests include condition monitoring of transformers, wind energy conversion, power quality and harmonics, and power systems. He has been a keynote speaker and an invited speaker at many international workshops and conferences.

Dr. Islam is currently the Vice-Chair of the Australasian Committee for Power Engineering. He is a member of the board of Directors of the Australian Power Academy, and a Fellow of the Engineers Australia and the Institution of Engineering and Technology. He is also a Chartered Engineer in the United Kingdom. He was the recipient of the IEEE T. Burke Haye's Faculty Recognition Award in 2000. He is a regular Reviewer for the IEEE TRANSACTION ON ENERGY CONVERSION AND POWER DELIVERY and an Editor of the IEEE TRANSACTION ON SUSTAINABLE ENERGY.

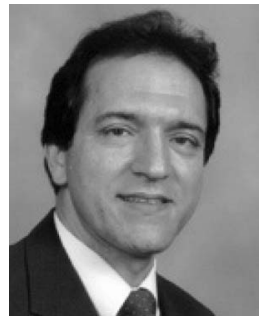

Mohammad A. S. Masoum (S'88-M'91-SM'05) received the B.S., M.S., and Ph.D. degrees in electrical and computer engineering from the University of Colorado, Boulder, in 1983, 1985, and 1991, respectively.

$\mathrm{He}$ is currently an Associate Professor and the Head of the Discipline for Electrical Power Engineering, Department of Electrical and Computer Engineering, Curtin University of Technology, Perth, Australia. His main research interests include optimization, power quality and stability of power systems, and distributed generation. He is the coauthor of Power Quality in Power Systems and Electrical Machines (Academic Press, Elsevier, 2008). 